\title{
Immunodominant membrane proteins from two phytoplasmas in the aster yellows clade (chlorante aster yellows and clover phyllody) are highly divergent in the major hydrophilic region
}

\author{
Derek J. Barbara, ${ }^{1}$ Anne Morton, ${ }^{1}$ Michael F. Clark ${ }^{2}$ and David L. Davies ${ }^{2}$
}

Author for correspondence: Derek J. Barbara. Tel: +44 1789 470382. Fax: +44 1789470552. e-mail: Dez.Barbara@HRI.AC.UK

1 Plant Pathology and Microbiology, Horticulture Research International, Wellesbourne,

Warwickshire CV35 9EF, UK

2 Entomology and Plant Pathology, Horticulture Research International, East Malling, West Malling, Kent ME19 6BJ, UK

\begin{abstract}
The mechanisms by which phytoplasmas interact with their hosts are not understood. Mollicute membrane proteins may play a role in such interactions and therefore the amp genes encoding immunodominant proteins from two phytoplasmas, aster yellows and clover phyllody, which fall within the largest taxonomic subclade of the phytoplasmas, have been cloned and characterized. The putative translation products, antigenic membrane proteins (Amps), of these genes have properties which are typical for bacterial membrane proteins, and which suggest that each has a single large extracellular hydrophilic domain held by a transmembrane region near the C-terminus, with only a short C-terminal intracellular sequence. Both of the Amps characterized here have bacterial leader sequences which are cleaved during maturation. Whilst the signal peptide and transmembrane regions of the two proteins are very similar, the major hydrophilic domains are highly divergent in both size and sequence. The Amps from the two phytoplasmas are also different in structure and sequence from the immunodominant membrane proteins of three other phytoplasmas whose genes have been cloned previously.
\end{abstract}

Keywords: serological detection in planta, host-pathogen interactions

\section{INTRODUCTION}

Phytoplasmas are wall-less prokaryotes with small genomes (approximately 0.53-1.35 Mbp; Neimark \& Kirkpatrick, 1993; Marcone et al., 1999) and low G + C contents (about $25 \mathrm{~mol} \%$ ). They are most closely related to the genus Acholeplasma within the order Mollicutes (see Seemüller et al., 1998, for a review of the classification of phytoplasmas). Phylogenetically they are thought to form a monophyletic clade within the Anaeroplasma clade and to be evolutionarily derived from a Grampositive, Clostridium-like bacterial ancestor (Lee et al., 2000). Phytoplasmas are transmitted by plant- and leaf-

Abbreviations: $A M P$, antigenic membrane protein; $A P$, apple proliferation; AY, aster yellows; AY-C, chlorante isolate of aster yellows; AY-PY, primula yellows isolate of aster yellows; $\mathrm{CP}$, clover phyllody; $\mathrm{E} / \mathrm{H} / \mathrm{T}$, export leader, hydrophilic and transmembrane domains, respectively, in the putative AMP; SPWB, sweet potato witches' broom phytoplasma; WX, western $\mathrm{X}$ phytoplasma.

The GenBank accession numbers for the sequences reported in this paper are AF244540 and AF244541 for AY-C and CP, respectively. hoppers, and psyllids. In insect hosts they occur in the haemolymph, but must enter the salivary gland before transmission to their plant host. Once in the plant they are restricted to the phloem. Phytoplasmas are responsible for several hundred diseases, many of which are economically destructive, in a wide range of plants. Although some phytoplasmas do occur in temperate climates, the most important are found in the tropics and subtropics (McCoy et al., 1989).

Despite the fact that they clearly multiply freely in both plant and insect hosts, no phytoplasma has yet been grown in vitro. Many other members of the Mollicutes, notably within the genera Mycoplasma and Spiroplasma, may be grown in vitro, but have been shown to interact very specifically with host-cell membranes in vivo (Razin \& Jacobs, 1992; Yu et al., 2000). We have proposed (Barbara et al., 1998) that such interactions with the host are essential, rather than optional, for the growth of phytoplasmas. Serological studies have shown that in many phytoplasmas a single, reasonably abundant surface membrane protein is immunodominant 
(Clark et al., 1983, 1989). In other cases it has been found that several proteins in the membrane preparations are strongly antigenic; e.g. four and three proteins have been found, respectively, for the flavescence dorée and elm yellows phytoplasmas (Seddas et al., 1996), which are serologically related members of the same subclade (Lee et al., 2000). These antigenic membranes proteins (AMPs) are known to be serologically variable between phytoplasmas (e.g. Clark et al., 1983, 1989) and have been shown, by immunogold-labelling in electron microscopy studies, to be located on the external surface of the cell (Milne et al., 1995). They are, therefore, good candidates to be at least one of the phytoplasma components involved in host-pathogen interactions. Preliminary evidence for one phytoplasma, the grapevine pathogen flavescence dorée, suggests that some unidentified pathogen-specific material in phytoplasmaenriched preparations will bind to insect cells (Lefol et al., 1993).

Phytoplasma classification is currently based mainly on 16S rRNA gene sequences (Seemüller et al., 1998). Aster yellows (AY) and related phytoplasmas form the largest division of the phytoplasmas in cladograms based on such data. Chlorante AY (AY-C) and clover phyllody (CP) are two serologically distinct phytoplasmas (Clark et al., 1983, 1989) that have been placed in separate subclades (IB and IC; Lee et al., 2000) on the basis of $16 \mathrm{~S}$ rRNA sequence data; this separation is supported by phylogenetic analysis of tuf gene sequences (Marcone et al., 2000). Both AY-C and CP are known to have single AMPs (Clark et al., 1983, 1989).

The long-term aim of our project is to examine whether specific membrane proteins have any role in phytoplasma-host interactions. The first steps, as reported here, were the cloning and sequencing of the amp genes encoding the Amps from AY-C and CP phytoplasmas. Phytoplasma membrane proteins are difficult to purify from infected hosts; hence efficient in vitro expression of the proteins was developed both to allow serological confirmation that the correct genes had been cloned and to provide materials for planned studies into the interactions of these proteins with host components. A polyclonal antiserum raised against expressed CP Amp was tested as a reagent for the detection of this phytoplasma in plants. The AY and CP amp genes were compared with the genes for immunodominant proteins that have been recently cloned from phytoplasmas in other subclades, viz. apple proliferation (AP; Berg et al., 1999), sweet potato witches' broom (SPWB; Yu et al., 1998) and western X (WX; Blomquist et al., 2001), and the results are also reported here.

\section{METHODS}

Isolates. The isolates of AY-C (also known as rape virescence), probably originally from rape (Brassica napus) (Vibio et al., 1996), and CP used for the majority of this work were maintained in Catharanthus roseus in a glasshouse with supplementary lighting and heating. Transfers between plants were by cleft-graft inoculation. An additional new isolate of $\mathrm{CP}$ was obtained from a commercial planting of strawberries which showed strawberry green petal disease (CP and strawberry green petal diseases are induced by the same phytoplasma : Posnette \& Ellenberger, 1963; Clark et al., 1983). The identity of the additional CP isolate was confirmed by PCR analysis using the conserved $16 \mathrm{~S}$ rRNA gene primers U5 and U3 (Lorenz et al., 1995). Primula yellows (AY-PY) phytoplasma was maintained in $C$. roseus as above. AY-PY is a member of the same 16S rRNA subclade as AY-C (Vibio et al., 1996; Lee at al., 2000), although Marcone et al. (2000) have placed it in another $16 \mathrm{~S}$ rRNA-based subclade, IL, whilst keeping it within the largest $t u f$ gene subclade, IB.

Protein isolation and sequencing. For immunoaffinity purification of the AMP of AY-C from crude preparations (Clark et al., 1983, 1989), monoclonal antibodies (mAbs) raised against AY-PY (Clark et al., 1989) were mixed with extracts from infected C. roseus $(200 \mu \mathrm{g}$ mAbs per $2 \mathrm{ml}$ extract, equivalent to $6 \mathrm{~g}$ infected tissue) in GM buffer $(0.3 \mathrm{M}$ glycine, $0.05 \mathrm{M}$ $\mathrm{MgCl}_{2}, 0 \cdot 1 \mathrm{M} \mathrm{NaCl}, 50 \mathrm{~g}$ sucrose $\mathrm{l}^{-1} ; \mathrm{pH} \mathrm{8.0)}$ and held at $4{ }^{\circ} \mathrm{C}$ for $2 \mathrm{~h}$. Phytoplasma-antibody complexes were sedimented by centrifugation $(60000 \mathrm{~g}, 30 \mathrm{~min})$ to separate them from unbound antibodies. Pellets were resuspended in GM buffer before mixing with a suspension of magnetic beads coated with goat anti-mouse antibodies. The mixture was further incubated for $2 \mathrm{~h}$ at $4{ }^{\circ} \mathrm{C}$, and the beads were then collected magnetically and washed with GM buffer. The phytoplasmaantibody complexes were eluted from the beads with SDSelectrophoresis loading buffer (Laemmli, 1970). Proteins in the extracts were separated by discontinuous electrophoresis on $1 \mathrm{~mm}$ thick, $12 \%$ polyacrylamide gels. Gels were stained with Coomassie blue, the AMP band was excised, and the excised gel fragments were transferred to a second $1.5 \mathrm{~mm}$ thick $12 \%$ gel so that the proteins could again be separated electrophoretically. Chemical cleavage of the AMP was achieved by treating the excised gel fragments containing the protein with $15 \mathrm{mM} \mathrm{N}$-chlorosuccinimide in acetic acid/urea buffer (Lischwe \& Ochs, 1982) before the second electrophoresis step. Enzyme digestion was achieved by overlaying excised gel slices containing the AMP in the wells of the gel used for the second electrophoresis step with a solution of Glu-C protease (Sigma). During electrophoresis the current was switched off for $40 \mathrm{~min}$ before the tracking dye reached the stackingseparation gel interface to allow proteolysis to proceed; separation was then resumed as normal (Cleveland et al., 1977). For amino acid sequencing of the intact AMP or its cleavage products, protein bands were electroblotted onto a PVDF membrane after the second electrophoresis step. All protein sequencing was done by micro-Edman degradation, using a commercial service (Alta BioSciences).

Preparation of DNA and PCR. DNA was prepared from plants as described by Ahrens \& Seemüller (1992). All PCR, including inverse PCR (Ochman et al., 1990), used standard methods.

Cloning and sequencing. For AY-C, degenerate PCR primers were designed from the amino acid sequences generated as above using the standard genetic code because there is no evidence that the UGG codon is used for tryptophan rather than as a stop codon (as is the case in Mycoplasma, Spiroplasma and some other Mollicutes; Bové et al., 1989). Where appropriate, allowance was made for the probable low $\mathrm{G}+\mathrm{C}$ content of the genome when choosing between possible codons. Codon usage was also examined in the limited number of phytoplasma genes already characterized (data not shown). Other primers were based on the sequence initially obtained. For CP, amplification of the amp gene from CP used primers based on the AY-C amp gene sequence; various primer pairs were tested and several resulted in successful amplification. The largest amplicon spanning the amp gene was produced by 
primers 430 (5'-AAAAACTAGGTTAAAAAACCTAGC-3') and 427 (5'-CTGGCTTTACTTTTGTTTAGAAC-3').

All cloning of the PCR products into non-expression vectors used pMOS-Blue (initially as a 'T-A system', but later as a blunt-end ligation system; both were used according to the manufacturer's instructions; Amersham). Cloning into the expression vector pLEX (Invitrogen) was done by using PCR to introduce appropriate restriction endonuclease sites (and where appropriate stop codons) into amplicons which could then be cloned in-frame (NdeI and $\mathrm{XbaI}$ sites in the multiple cloning site for AY-C; NdeI and PstI sites for CP). Termination codons were introduced into the AY-C clones. This strategy added a leucine-glutamine pair to the C-terminus of expressed CP proteins, but not to the AY-C proteins. PCRs intended for producing amplicons to be cloned into the expression vectors used template DNA from infected plants rather than clones in pMOS-Blue.

All sequencing was done by a commercial service (Sequiserve). Except in a few limited cases, it was assumed that the low $\mathrm{G}+\mathrm{C}$ content of the phytoplasma genome would mean that the PCR primers would not be good sequencing primers. The sequence data presented here were generated using conserved primers based on the plasmids used. Where large amplicons were sequenced, some initial data were obtained using sequencing primers based on the initial sequence obtained from the ends of those amplicons, but all such sequence data were confirmed by sequencing other clones that covered the same regions using conserved primers. All sequences relating directly to amp genes were confirmed by sequencing at least three separate clones (and in the case of CP, amplicons from several isolates).

Sequence assembly and analysis was completed using either GeneJockey II or DNAStar software. Other analyses were done via the EMBL web site (http://www2.ebi.ac.uk).

Protein expression and analysis. Protein expression from pLEX (Invitrogen) was done according to the supplier's instructions. Bistris/HCl/SDS-PAGE gels were obtained commercially (Novex and Invitrogen) and were used according to the manufacturers' instructions with the MES buffer supplied. Staining and Western blot analysis were done by standard procedures (Sambrook et al., 1989).

Antiserum production. The preparation of polyclonal antisera and $\mathrm{mAbs}$ to $\mathrm{CP}$ - and AY-associated antigens extracted from plants has been described previously (Clark et al., 1983, 1989). A polyclonal antiserum to CP Amp expressed in Escherichia coli was prepared in a New Zealand White rabbit by four injections at fortnightly intervals. All injections comprised about $500 \mu \mathrm{g}$ total protein from the fraction pelleted by centrifugation from lysed bacterial cells. For the first injection the cells carried a plasmid expressing the entire ORF, but on the three other occasions a plasmid expressing only the leader sequence and main hydrophilic domain was used (see Results for details of clones).

\section{RESULTS}

\section{Initial protein analysis for AY-C}

As found previously (Clark et al., 1989), phytoplasmaenriched preparations (prepared using an immunoprecipitation step) from AY-C had a strong single protein band of approximately $22.4 \mathrm{kDa}$ in SDS-PAGE gels. Initially, the sequence of the first 20 aa of the $\mathrm{N}$-terminus (with one ambiguity at position 11) was derived from the intact AMP. Cleavage fragments of the AMP generated by $\mathrm{N}$-chlorosuccinimide and Glu-C protease treatment were sequenced to generate data from within the protein. $\mathrm{N}$-Chlorosuccinimide cleavage gave three clear products (with other smaller products running at the electrophoretic front), the two largest of which were sequenced. Cleavage was apparently incomplete, as a band corresponding in size to the uncleaved product was seen, the approximate total apparent molecular mass of the cleavage products was found to be greater than that of the original protein, and two bands had identical 12 aa N-terminal sequences. Four bands were seen following Glu-C protease digestion, which also appeared to be incomplete; three of these bands were sequenced.

\section{Cloning the AY-C amp gene}

Initially, inverse PCR using degenerate primers designed from the 20 aa $\mathrm{N}$-terminal sequence led to the cloning of a potential ORF, but further study suggested that this did not encode the Amp. In a second attempt to clone the amp gene, degenerate primers were designed based on the amino acid sequences of the protein fragments. Since the order of the fragments was not known, primers were designed in both directions for each fragment (except for the primer based on the $\mathrm{N}$-terminal sequence of the intact protein). All possible pairs of primers were used in PCR and several amplicons of various lengths were produced; the longest of these were cloned and sequenced. Non-degenerate primers based on these new sequence data were then used in inverse PCR to extend the original sequence until an approximately $2375 \mathrm{bp}$ contig was constructed. As was expected from the known properties of phytoplasma genomes, the contig had a low $\mathrm{G}+\mathrm{C}$ content $(27 \cdot 1 \mathrm{~mol} \%)$, suggesting that the sequence was phytoplasmal, not host-derived.

Analysis using the standard genetic code identified two large ORFs (one complete and one partial) and one possible small incomplete ORF within the contig (Fig. 1). The two intergenic regions were quite different in length. There was a probable RBS (AAAGGAG) upstream from the translation start site of the complete ORF which would pair with the reported nucleotide sequence two removed from the $3^{\prime}$-terminus of the AY 16S rRNA molecule (ucUUUCCUC) (Kuske \& Kirkpatrick, 1992). Possible transcription signals were located nearby ( -35 ; TTGTTA: -10 ; TATAAT). Short, slightly imperfect, inverted repeats occurred just downstream of the complete ORF (TTTAAAAAGCT AGGTTTTTTAA) and these may act as a transcription terminator. A shorter sequence (AAGGA) may form an RBS for the small incomplete ORF; however, no convincing transcription signals were found preceding it. Searches of the GenBank, EMBL and Swissprot databases using the sequence of the putative translation product of the large incomplete ORF (316 aa) showed strong matches with the C-terminal portion of chaperonin (GroEL) genes from various organisms, and the ORF probably represents about $60 \%$ of the homologous gene. The best matches for the ORF were found with the chaperonins of other members of the Bacillus/Clos- 


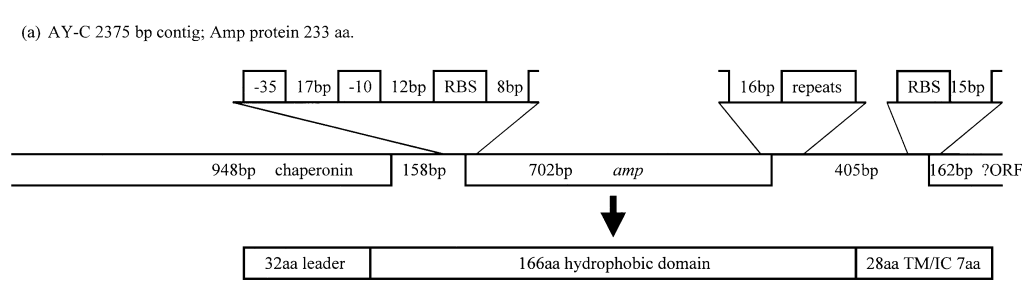

(b) CP 1191 bp contig; Amp protein 166 aa.

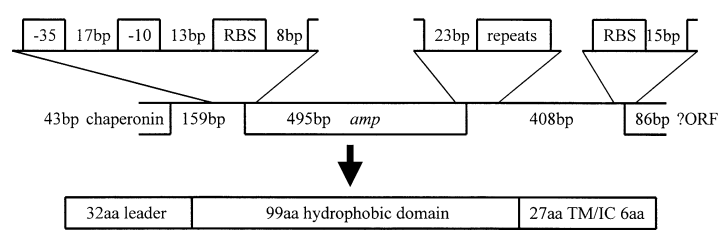

Fig. 1. Schematic representation of the ORFs and other features for the (a) AY-C and (b) $\mathrm{CP}$ contig sequences (top) and putative Amp translation products (bottom). -35 and -10 , possible transcription signals; RBS, putative ribosome-binding site; amp, antigenic membrane protein gene; repeats, short inverted repeats; ?ORF, possible ORF of unknown function; leader, predicted bacterial export leader sequence; TM/IC, transmembrane domain/hydrophilic intracellular C-terminal sequence.

\begin{abstract}
36-LDLNTLECKDALELTAAD AADAEKVVKQWKVQNTSLNAKVTKDSVK VVVADN KVTV-91

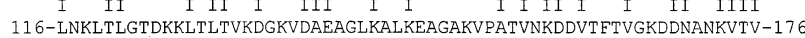

Fig. 2. Alignment of parts of the sequences for the major hydrophilic domain of AY-C Amps to show two poorly conserved repeats within AY-C. Numbers at the ends of the sequences refer to positions within the sequence of the entire ORF translation product.

Table 1. Sequence identities between AY-C and CP contigs and domains of the putative Amps based on simple CLUSTAL alignments

\begin{tabular}{|lc|}
\hline Sequence & Identity $(\%)$ \\
\hline DNA & \\
Intergenic spacer 1 & 94 \\
amp ORF & \\
$\quad$ Leader & 95 \\
Hydrophilic domain & $40 *$ \\
Hydrophobic C-terminal & 82 \\
Intergenic spacer 2 & 94 \\
Downstream ORF & 95 \\
AMP protein & \\
Leader & 88 \\
Hydrophilic domain & $15 \dagger$ \\
Hydrophobic domain & 68 \\
C-terminal & 86 \\
\hline
\end{tabular}

* The value given is an overestimate due to major differences in sequence length.

† If the major part of the CP sequence is treated as equivalent to a single repeat in the AY-C sequence the value would be approximately $20 \%$ (see text).

tridium group of the Firmicutes, particularly Lactobacillus johnsonii (accession no. AF214488) and Listeria monocytogenes (GenBank accession no. AF335323). Equally good matches were found with some members of the Proteobacteria, e.g. Helicobacter pylori (accession no. P42383). Several of these matches showed more than $50 \%$ identity with $75 \%$ similarity for spans of more than 100 aa with no gapping. Matches with chaperonins from other Mollicutes, such as Mycoplasma genitalium (GI no. 12045254), were clear, but less strong than those detailed above. No significant sequence matches were found for the small incomplete ORF.

\section{Identification and characterization of the AY-C amp gene product}

The large, apparently complete ORF (Fig. 1) was assumed to represent the amp gene and was analysed more intensively. The $\mathrm{G}+\mathrm{C}$ content was high relative to the rest of the contig, with a value of $32.9 \mathrm{~mol} \%$. The putative translation product of this ORF was a 233 aa protein, rich in valine $(17.6 \mathrm{~mol} \%)$, lysine $(14.6 \mathrm{~mol} \%)$ and alanine $(12.4 \mathrm{~mol} \%)$, and with two cysteine residues. The N-terminal 32 aa are relatively hydrophobic and properties of this segment suggest it forms a bacterial export leader sequence with a predicted cleavage point between residues 32 and 33 (von Heijne, 1990; Nakai \& Kanehisa, 1991; Nielsen et al., 1997; computer analysis using PSORT, version 6.4). The $\mathrm{N}$ terminal sequence of the intact protein purified from plants matched (except for the ambiguous residue) the predicted sequence from residues 33 to 52 and for the sequences from the protein fragments all matches began after residue 33 which was consistent with cleavage occurring between positions 32 and 33 during export. Of the 78 aa unambiguously identified by protein sequencing only one did not match the predicted sequence (a valine for a tryptophan). At a second position, overlapping peptides did not agree, but one of these did agree with the predicted sequence. There was a second hydrophobic region towards the C-terminus which was predicted to form a transmembrane region (at amino acids 204-226) with the C-terminus in the cytoplasm (TMpred; Hofmann \& Stoffel, 1993; PSORT). Both the large central and the short C-terminal domains were strongly hydrophilic. These predicted properties of the putative translation product strongly suggested that when it is expressed, the 32 aa leader is cleaved during export to leave a large hydrophilic extracellular domain anchored to the cell membrane by the transmembrane domain near the C-terminus, with only a short $(7 \mathrm{aa})$ C-terminal region in the cytoplasm. The majority of 


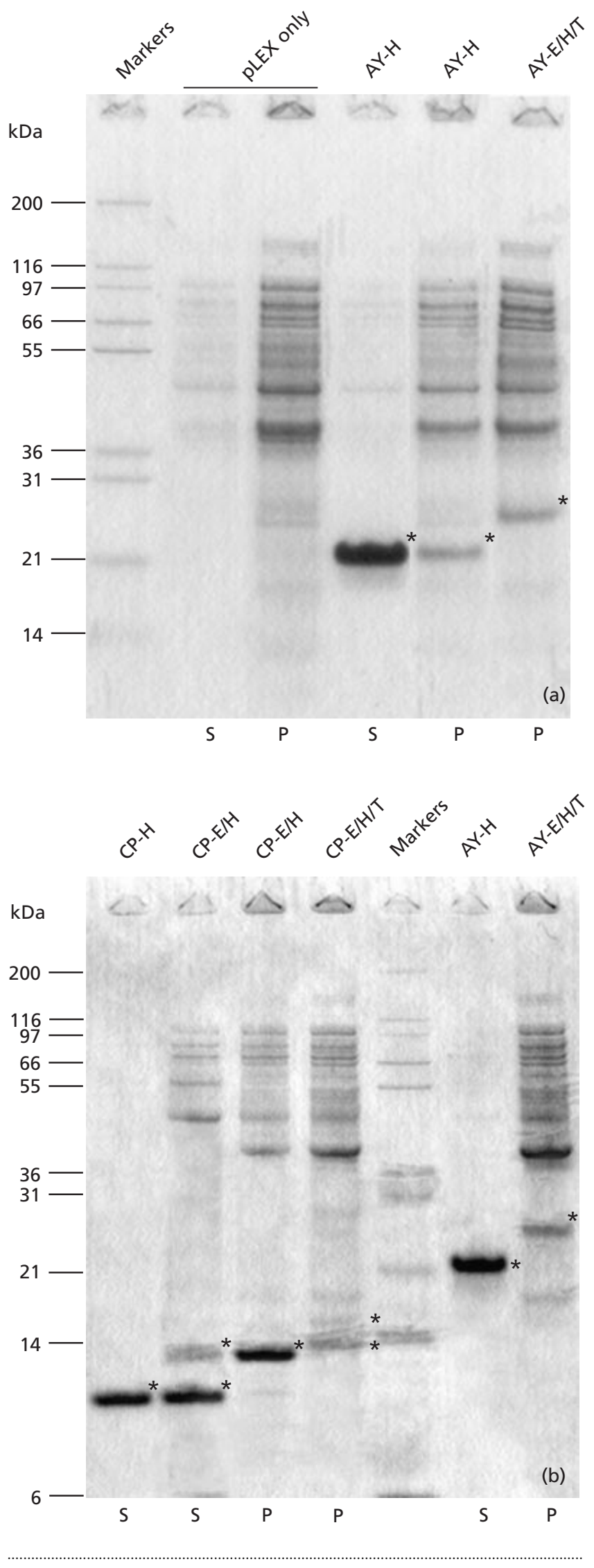

the large hydrophilic domain seemed to comprise two poorly conserved repeats of 56 and 61 aa (Fig. 2) which shared about $40 \%$ identity with only a limited introduction of gaps.

\section{Cloning and characterization of the CP amp gene}

To clone the amp gene from CP, primers designed from the AY-C contig were used in various pairwise combinations in PCR with DNA extracted from CP-infected C. roseus plants as a template. All primers were designed from sites outside the AY amp ORF and included some that had been used during the creation of the AY-C contig and others that were designed based on sequences within the two flanking ORFs (on the basis that these might be more conserved than the intergenic regions). The largest amplicon was cloned and sequenced and analysed as described above.

To confirm the sequence, and to determine whether any sequence changes had occurred during culture of the original isolate in C. roseus, the same primers were used to produce the equivalent amplicon using template DNA from two other isolates held in the greenhouse and one from a natural infection in a field-grown strawberry plant with strawberry green petal disease. When sequenced, all three of these amplicons were identical to the original.

As expected from the positions of the primers in the AY$\mathrm{C}$ sequence, the CP-derived sequence (Fig. 1) had short regions homologous to the two partial ORFs in AY-C. The overall $\mathrm{G}+\mathrm{C}$ content was $23 \mathrm{~mol} \%$. One complete ORF (495 bp; G $+\mathrm{C}$ content $35 \mathrm{~mol} \%$ ) encoding a putative 164 aa protein was present. A potential RBS (AAAGGAG) and transcription signals similar to those in AY-C $(-35$; CTGTTA: -10 ; TATGAT) were located upstream of the translation start codon. Downstream of the translation terminator were a pair of short inverted repeats (TTAAAAAAGCT - AGGTTTTTTAA). The putative translation product from the complete ORF had similar domains to those in the AY-C Amp (Fig. 1), i.e. a hydrophobic leader sequence at the $\mathrm{N}$-terminus with a predicted cleavage site between residues 32 and 33, a probably extracellular hydrophilic domain (smaller than that in AY-C), a hydrophobic region with predicted transmembrane region (at amino acids 142-158) and a short hydrophilic C-terminal

Fig. 3. $P A G E$ of protein expressed from $A Y-C$ and $C P$ clones in pLEX. After lysis of induced cultures the extracts were centrifuged to separate insoluble and membrane-bound material from soluble material. $S$ and $P$ indicate supernatant and pellet fractions, respectively. Bands representing protein induced from the cloned sequences are indicated with asterisks. (a) Comparison of cell extracts with pLEX only and extracts of cells with the clones indicated $4 \mathrm{~h}$ after induction. (b) Comparison of the relative mobilities of the main products from both $\mathrm{CP}$ and $\mathrm{AY}-\mathrm{C}$ clones. Note the presence of two specific bands in two tracks representing $C P-E / H$ and $E / H / T$ clones. A Mark12 wide range protein standard (Novex and Invitrogen) molecular mass marker was used to determine the size of the fragments. 
Table 2. Subcellular localization and approximate molecular masses as estimated by SDS-PAGE of expressed Amp from two AY-C and four CP clones

\begin{tabular}{|llcc|}
\hline Phytoplasma clone* & Expected mass $(\mathrm{Da}) \dagger$ & \multicolumn{2}{c|}{ Molecular mass $(\mathrm{Da})$ of protein in } \\
\cline { 3 - 4 } & & Supernatant $\neq$ & Pellet \\
\hline $\mathrm{AY}-\mathrm{C}$ & & - & 26900 \\
$\mathrm{E} / \mathrm{H} / \mathrm{T}$ & 21325 (cleaved) & & - \\
$\mathrm{H}$ & 24800 (uncleaved) & 23450 & \\
$\mathrm{CP}$ & 17217 & - & 13950 \\
$\mathrm{E} / \mathrm{H} / \mathrm{T}$ & & 8500 & 12600 \\
$\mathrm{E} / \mathrm{H}$ & 14207 (cleaved) & +12600 & 13800 \\
$\mathrm{H} / \mathrm{T}$ & 17850 (uncleaved) & - & - \\
$\mathrm{H}$ & 10165 (cleaved) & 8500 & (uncleaved) \\
\hline
\end{tabular}

* Parts of amp genes present in clones used for expression. E, N-terminal export leader sequence; H, large hydrophilic domain; T, transmembrane/short C-terminal hydrophilic domain.

† Expected size (including the Leu-Gln pair added to CP sequences).

$\ddagger$ Fractions after centrifugation. - , No or only a trace of expressed protein present; + , for the CP E/H clone both the 8500 and 12600 Da proteins appear in the supernatant. For the CP E/H/T clone both the 13950 and the 16600 Da protein appear in the pellet.

region. The computer prediction (PSORT) for the presence of a leader sequence was not as strong for CP Amp (4.41) as for AY-C Amp (6.06). As with AY-C, the putative translation product was rich in valine $(15.9$ $\mathrm{mol} \%)$, lysine $(11.0 \mathrm{~mol} \%)$ and alanine $(12.2 \mathrm{~mol} \%)$. The CP sequence had no cysteines.

Sequence comparisons of AY-C and CP. The level of nucleic acid sequence identity between AY-C and CP varied considerably. Sequence identities for the intergenic regions were high (Table 1), except in short regions immediately following the translation terminator codons for the amp ORFs (TCTTATTTAATCATTA in AY-C and TTAATCCCTAAATTATATTCTTT in CP) which cannot be easily aligned. Immediately following these short sequences were the repeats which may form the transcription stop signals and the short divergent sequences which may represent the $3^{\prime}$-UTR of the mRNAs. Within the amp ORFs, levels of identity also varied greatly. For those regions predicted to encode the large hydrophilic domains identity was low, but identity was high for the other regions (Table 1). Comparisons at the amino acid level also gave strikingly varied levels of identity. The hydrophobic leader sequence, the transmembrane region and the short hydrophilic C-terminal part were all conserved in both length and sequence between the two phytoplasmas, but the main hydrophilic domain differed greatly in both length and sequence (Fig. 1; Table 1). In CP there was no evidence of poorly conserved large repeats similar to those seen with AY-C, but the majority of the hydrophilic domain could be aligned with the second AY-C repeat (but with only about $20 \%$ of the amino acids identical).
Sequence comparisons of AY-C and CP Amps with immunodominant membrane proteins from other phytoplasmas. No significant sequence similarity was found between the Amp sequences of either AY-C or CP and the known sequences for immunodominant membrane proteins from AP (AJ011678; Berg et al., 1999), SPWB (U15224; Yu et al., 1998) and WX (AF225904; Blomquist et al., 2001) phytoplasmas.

Sequence comparisons of other protein sequences. For both AY-C and CP Amps, simple database searches gave no significant matches for sequence similarities nor did searches for functional motifs (other than the bacterial leader sequence/cleavage point and transmembrane region), with one exception: when $\mathrm{AY}-\mathrm{C}$ sequence was used to scan RELIBASE (http://www2.ebi.ac.uk), a database of ligand-binding proteins, a clear match was found against a short peptide (C2) from protein G, an IgG Fc-binding protein from a Streptococcus sp. The region of greatest identity (10/13 residues) corresponded with part of the peptide that forms an $\alpha$-helix, which is closely associated with the site of binding to the IgG molecule (Sauer-Eriksson et al., 1995). Searching RELIBASE with the CP Amp sequence did not produce a similar match, but both the two 'repeats' in AY-C and the CP sequence showed four or five identical amino acids in the same region.

Comparisons of flanking sequences. No significant similarity was apparent between the putative intergenic regions either side of the Amp ORFs of the AY-C/CP pair, AP, SPWB or WX. Both AY-C and CP have a putative chaperonin as their upstream ORF (about $60 \%$ sequenced for AY-C, but only a short sequence from the 

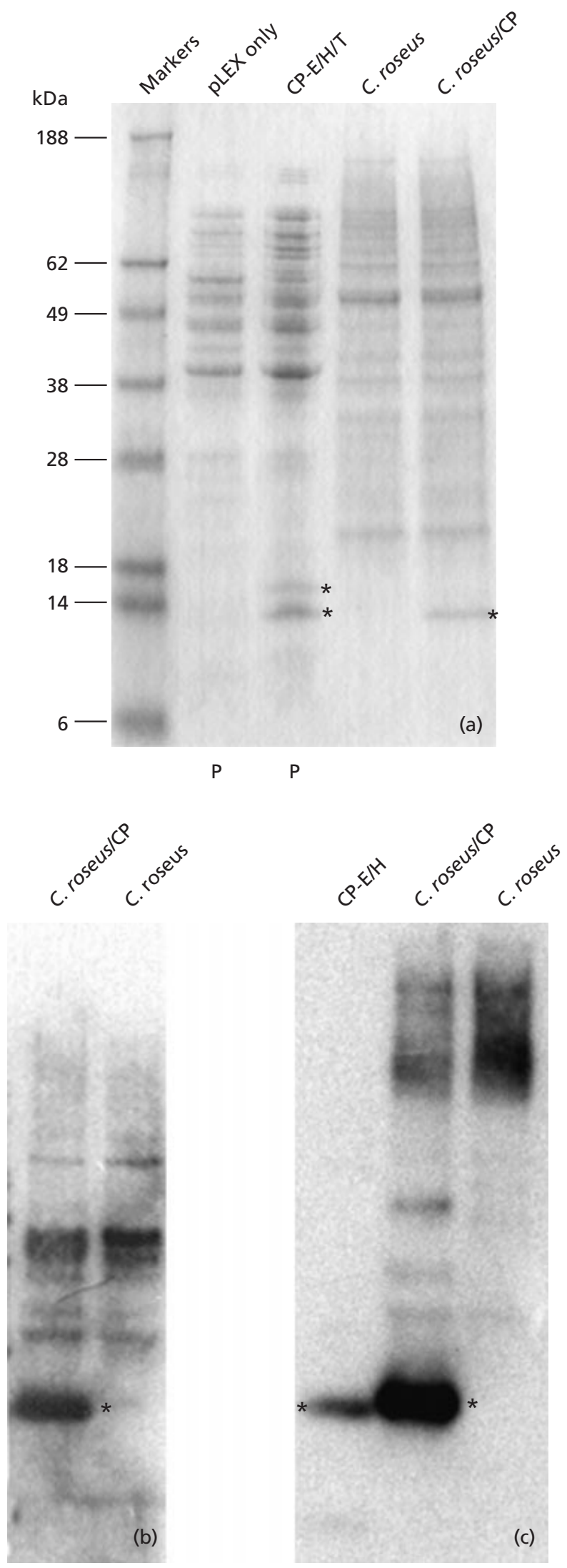

C-terminus was obtained from CP). The WX immunodominant protein gene $(i d p)$ has a probable DNA polymerase gene upstream (Blomquist et al., 2001). Both AP and SPWB immunodominant membrane protein genes have upstream ORFs of unknown function which share strong similarities $(40 \cdot 7 \%$ identical residues with no gaps introduced) (Berg et al., 1999; Yu et al., 1998). These unidentified ORFs have no significant similarity to chaperonin genes or to DNA polymerase genes.

\section{Expression of Amps in E. coli and serology}

Using the vector pLEX, a series of stable clones expressing various domains of both AY-C and CP were obtained. For AY-C these comprised the entire ORF $(\mathrm{E} / \mathrm{H} / \mathrm{T})$ or the main hydrophilic domain alone $(\mathrm{H})$. Despite two attempts, no clones of the hydrophilic domain with the leader sequence $(\mathrm{E} / \mathrm{H})$ or of the hydrophilic domain with the C-terminal transmembrane region $(\mathrm{H} / \mathrm{T})$ could be obtained. For $\mathrm{CP}$ all four types of construct $(\mathrm{E} / \mathrm{H} / \mathrm{T}, \mathrm{H}, \mathrm{E} / \mathrm{H}, \mathrm{H} / \mathrm{T})$ attempted were produced successfully. Generally good levels of expression were obtained following induction from the six clones used (Fig. 3), but for both phytoplasmas clones comprising the entire ORF $(\mathrm{E} / \mathrm{H} / \mathrm{T})$ always produced lower levels of protein than the other clones.

Only single additional bands were seen after induction for the two AY-C clones. For these clones, the partitioning of expressed protein into either the supernatant or pellet fractions, after centrifugation of lysed cells, was as expected, but the apparent molecular masses were approximately $6 \mathrm{kDa}$ greater than predicted (Table 2 ). In contrast, for $\mathrm{CP}$ both of the clones containing the leader sequence had two additional bands, either in the pellet fraction $(\mathrm{E} / \mathrm{H} / \mathrm{T}$, although the smaller band was not always seen) or in the supernatant $(\mathrm{E} / \mathrm{H})$. The CP $\mathrm{E} / \mathrm{H}$ clone, unexpectedly, also had an additional band in the pellet fraction. In CP, the apparent molecular masses were always $0 \cdot 3-1 \cdot 6 \mathrm{kDa}$ less than expected. However, the band assumed to correspond to the $\mathrm{H} / \mathrm{T}$ domains cleaved from the $\mathrm{E} / \mathrm{H} / \mathrm{T}$ product was of the same apparent mass as plant-derived AMP when compared directly (Fig. 4). These results suggested that the leader peptide had been entirely cleaved and all of the protein

Fig. 4. Comparisons by PAGE (a) and Western blots (b, c) of proteins expressed from clones in pLEX with extracts from CPinfected and uninfected $C$. roseus plants. All $E$. coli extracts were from the pellet fraction after centrifugation (P). Bands representing protein derived from clones $3 \mathrm{~h}$ after induction or phytoplasma-specific bands in infected plant extracts are indicated with asterisks. The blot in (b) was probed with antiserum raised against $E$. coli-expressed CP protein and the blot in (c) was probed with antiserum raised against plantderived antigens (Clark et al., 1983). The molecular mass markers used were as for Fig. 3. In (a) note that the fastermigrating band, presumably with leader sequence removed, comigrates with the plant-derived protein. In (c) the marginal differences in migration distances were due to the two amino acids added during the cloning procedure. 


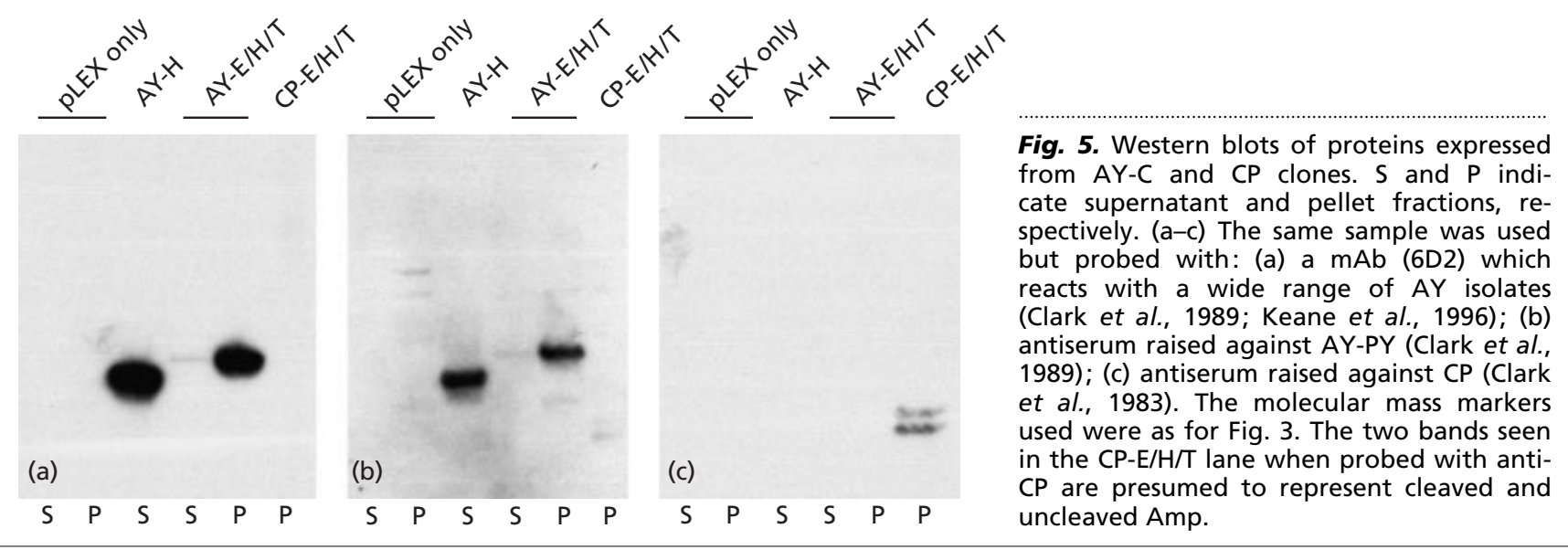

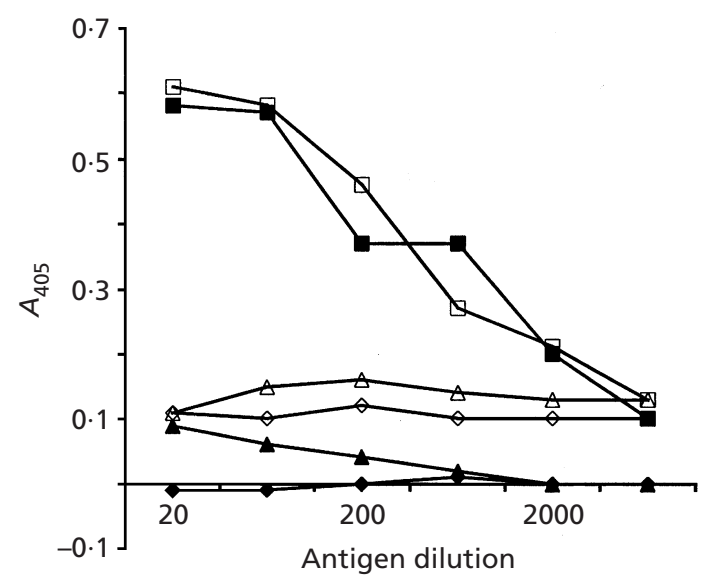

Fig. 6. ELISA for the detection of phytoplasmas in C. roseus. Antigen dilutions of between 1:20 and 1:6600 (w/v) were tested using either a polyclonal antiserum raised against CP Amp expressed in $E$. coli (solid symbols) or one raised against plant-derived CP antigen (open symbols) (Clark et al., 1983). $\diamond$, Uninfected; $\mathbf{\Delta}, \triangle, \mathrm{AY}-\mathrm{PY} ; \mathbf{\square}, \square, \mathrm{CP}$.

was embedded in the cell membrane for the AY-C $\mathrm{E} / \mathrm{H} / \mathrm{T}$ clone, but for the $\mathrm{CP} \mathrm{E} / \mathrm{H} / \mathrm{T}$ and $\mathrm{E} / \mathrm{H}$ clones cleavage was incomplete for the expressed Amp. When tested by Western blotting, expressed proteins were detected by polyclonal antisera raised against homologous plant-derived AMPs, but were not detected by the heterologous antisera (Fig. 5). Similarly, two mAbs raised against AY-PY (Clark et al., 1989) or AY-C (Keane et al., 1996) detected protein expressed from AYC-derived clones, but not protein expressed from CPderived clones. No CP-specific mAbs were available. Similarly, an antiserum raised against the CP Amp expressed in E. coli detected the protein derived from the $\mathrm{CP}$ clone product, but did not detect the protein derived from the AY-C clone. This same antiserum also reacted with AMP in extracts of CP-infected C. roseus (Fig. 4).

When used in a Fab'-based ELISA (Barbara \& Clark, 1982), the polyclonal antiserum raised against CP Amp expressed in E. coli clearly detected the homologous phytoplasmas in extracts of C. roseus, but gave no reaction with healthy plant extracts (Fig. 6). Surprisingly, as with antiserum raised against plant-derived antigens, dilution of the second antibody in healthy plant extract reduced the background reaction (although this was already lower than with the antisera to plantderived antigens). When used under comparable conditions, the antiserum to expressed proteins had reactions with the homologous phytoplasma similar to those seen with the antiserum raised against plant-derived antigens but, as a result of the lower backgrounds, enabled much more sensitive detection of the phytoplasmas in plant extracts (Fig. 6). The antiserum to expressed CP Amp gave weak but clear reactions with the AY-PY, but whereas the antiserum to plant-derived $\mathrm{CP}$ antigen gave slightly higher reactions to AY than to healthy plants there was no reduction in absorbance with antigen dilution and therefore no convincing cross-reaction with the heterologous phytoplasma and this antiserum.

\section{DISCUSSION}

The serological data and, for AY-C, the agreement between the predicted Amp sequence and sequence obtained directly from the AMP isolated from plants demonstrated that the genes cloned were those for the AMPs. For both AY-C and CP, the DNA sequences suggested that the complete ORFs were typical bacterial genes with translation products that were typical bacterial membrane proteins. Each had N-terminal leader sequences which were removed during export to give mature proteins with a large extracellular $\mathrm{N}$-terminal hydrophilic domain and a single transmembrane region near the C-terminus. Each would have a short Cterminal domain within the cell. These properties are consistent with published evidence from electron microscopy studies, which show the antigens recognized by both polyclonal antisera and $\mathrm{mAbs}$ are located on the outside of the cell membrane (Milne et al., 1995). Two cysteines are present in the AY-C Amp, but the absence of this amino acid in the CP Amp suggests that these residues are not likely to be needed for intramolecular cross-linking. For AY-C clones which included the 
leader sequence expression in E. coli appeared to lead to complete cleavage and appropriate positioning of the mature protein. However, for CP clones this cleavage appeared to be incomplete, leading to some protein being incorrectly positioned (e.g. the $\mathrm{E} / \mathrm{H}$ clone product being associated with the membrane fraction). This reflected poorer predictions for a cleavable leader sequence in the CP Amp than in the AY-C Amp (based on PSORT). However, only single bands have been observed in plant-derived antigen, implying complete cleavage of the protein in vivo for both the phytoplasmas.

As might be expected for two phytoplasmas contained within subclades of a single clade, parts of the Amps (the $\mathrm{N}$-terminal leader, second transmembrane and short Cterminal region) were strongly conserved between the two phytoplasmas. However, the main hydrophilic domains differed greatly in size (166 aa for AY-C as opposed to 99 aa for $\mathrm{CP}$ ) and had low sequence similarity in simple alignments. This high divergence between the hydrophilic regions was emphasized by the high similarity at the nucleotide level between the flanking intergenic regions, which we had expected to be more divergent than the amp coding regions. As members of the same clade, albeit different subclades, AY-C and CP presumably share a common evolutionary origin. There was some suggestion from the AY-C sequence that a large part of its major hydrophilic domain comprised two poorly conserved repeats and that these corresponded to an equivalent part of the $\mathrm{CP}$ sequence. The surprisingly large length difference for the two proteins might therefore be explained by sequence duplication in the AY-C gene after this phytoplasma's lineage diverged from that of CP (or by repeat loss in $\mathrm{CP})$. The amp ORF appears to be approximately $10 \mathrm{~mol} \%$ more G + C-rich than the complete contigs for both phytoplasmas. For CP it may be argued that this results from the ORF being composed of codons, with consequent limitations on the tendency to lower $\mathrm{G}+\mathrm{C}$. However, for AY-C a large portion of the contig is the upstream chaperonin gene and this should also limit the reduction in $\mathrm{G}+\mathrm{C}$ content. The possible significance of the amp ORFs being somewhat more G + C-rich is unclear.

No sequence similarity was seen between either of the amp genes cloned here from the AY clade phytoplasmas and the membrane protein genes cloned from AP, SPWB and WX phytoplasmas (Yu et al., 1998; Berg et al., 1999; Blomquist et al., 2001) which are in the AP, faba bean phyllody and WX clades, respectively (Seemüller $e t$ al., 1998). All five proteins would appear to have major hydrophilic domains on the exterior of the phytoplasma. However, the SPWB and AP proteins are not anchored by a C-terminal transmembrane region, but rather by a non-cleavable $\mathrm{N}$-terminal transmembrane domain. The WX protein is similar to AY-C and $\mathrm{CP}$ in having two hydrophobic domains within the primary translation product, but in WX neither would appear to be removed by cleavage (Blomquist et al., 2001). This protein presumably presents the hydrophilic domain as a loop held between two membrane anchors. Despite these differences in secondary structure these proteins all represent a single immunodominant phytoplasma antigen in extracts from infected plants. However, we have no understanding of the function of any of these proteins and should not assume they are homologues. The variation in both structure and genomic locations would suggest that the sequences of three distinct genes from five phytoplasmas have now been reported: (i) for the immunodominant membrane proteins (Imp) from SPWB and AP (Yu et al., 1998; Berg et al., 1999), (ii) for the immunodominant protein (Idp) from WX (Blomquist et al., 2001) and (iii) for the antigenic membrane proteins (Amp) from AY-C and CP (this study). Why three different proteins should each be immunodominant in the different phytoplasmas is, as yet, unknown.

Phytoplasmas were once thought to be closely related to the genus Mycoplasma, and were referred to as ' $\mathrm{Myco-}$ plasma-like organisms' or MLOs. Phytoplasmas and mycoplasmas are both still classified in the order Mollicutes, with their ancestors thought to be similar to members of the Bacillus/Clostridium group of the Firmicutes. However, the relationship between the two is now thought to be less close (Lee et al., 2000) and this division might appear to be supported by the greater similarity of the phytoplasma chaperonin gene to genes from bacterial members of the Bacillus/Clostridium group than to those from Mycoplasma spp. However, both phytoplasmas and Mycoplasma spp. have very small genomes compared to their supposed bacterial ancestors and the apparent divergence may be due to loss of homologous genes during genome reduction. This explanation is supported by the sequence similarity between the phytoplasma chaperonin gene and (presumably homologous) chaperonin genes from Proteobacteria being as high as that found when comparing chaperonin genes from bacteria of the Bacillus/Clostridium group of bacteria amongst themselves.

ELISAs are effective methods for detecting phytoplasmas in hosts which, although perhaps not as sensitive as PCR and not able to detect as great a range of organisms as when using conserved primers for PCR, are very useful for rapid, cost-effective screening for specific organisms. Polyclonal antisera and $\mathrm{mAbs}$ have been raised against many phytoplasmas using plant-derived antigens. However, for reasons which are unclear, for some phytoplasmas no satisfactory antisera have been produced this way. The antiserum raised here to expressed Amp proved better at detecting the phytoplasma in plants than previously available antisera raised against plantderived antigens. Raising similar antisera would be a useful approach for other phytoplasmas where the immunodominant protein genes can be cloned but where no antisera are yet available. It would also be a costeffective alternative to $\mathrm{mAb}$ production.

Whilst the biochemical functions of the AMPs are still unknown, the high divergence between the exposed hydrophilic domains suggests that they are under strong selective pressure. In the light of our hypothesis that the 
AMP is associated with host-pathogen interactions at the cellular level, it is tempting to suggest that this variability may be related to host specificity. Although the AY-C AMP clearly does not function by binding IgG in vivo or in ELISAs, its similarity to part of the active site of an IgG-binding peptide from protein $G$ may suggest that the AY-C AMP has some ligand-binding function. The AMP and protein G (accession no. P19909; Olsson et al., 1987) have similar structures and cellular localization, and both occur in members of the Bacillus/Clostridium group of the Firmicutes. Taken with the sequence identity this may suggest that they are homologous proteins. However, as the evidence for similar sequences being present in the CP AMP is scant, the significance of these identities is as yet unclear.

The predicted properties of the Amps of AY-C and CP phytoplasmas are consistent with their being membrane proteins and the large difference between them, despite their being in the same rRNA clade, suggests they are under relatively strong divergent selective pressure and may, therefore, possibly have important functions. We are currently investigating whether such large differences occur between the main hydrophilic domain of homologues of membrane proteins from phytoplasmas in other clades. We have also begun to study whether direct interactions can occur between the Amps and host cell surface components.

\section{ACKNOWLEDGEMENTS}

This work was funded by the BBSRC through its core strategic grant to HRI.

\section{REFERENCES}

Ahrens, U. \& Seemüller, E. (1992). Detection of DNA of plant pathogenic mycoplasmalike organisms by a polymerase chain reaction that amplifies the sequence of the $16 \mathrm{~S}$ RNA gene. Phytopathology 82, 828-832.

Barbara, D. J. \& Clark, M. F. (1982). A simple indirect ELISA using $\mathrm{F}\left(\mathrm{ab}^{\prime}\right)_{2}$ fragments of immunoglobulin. J Gen Virol 58, 315-322.

Barbara, D. J., Davis, D. L. \& Clark, M. F. (1998). Cloning and sequencing of a major membrane protein from chlorante (AY) phytoplasma. In Proceedings of the 12th International Organisation of Mycoplasmology, Sydney, Australia, p. 183. Sydney: International Organisation of Mycoplasmology.

Berg, M., Davis, D. L., Clark, M. F., Vetten, H. J., Maier, G., Marcone, C. \& Seemüller, E. (1999). Isolation of the gene encoding an immunodominant membrane protein of the apple proliferation phytoplasma, and expression and characterization of the gene product. Microbiology 145, 1937-1943.

Blomquist, C. L., Barbara, D. J., Davies, D. L., Clark, M. F. \& Kirkpatrick, B. C. (2001). Cloning and characterization of a major membrane protein of the X-disease phytoplasma. Microbiology 147, 571-580.

Bové, J. M., Carle, P., Garnier, M., Laigret, F., Renaudin, J. \& Saillard, C. (1989). Molecular and cellular biology of spiroplasmas. In The Mycoplasmas, vol. V, pp. 243-364. Edited by R. F. Whitcomb \& J. G. Tully. San Diego, CA: Academic Press. Clark, M. F., Barbara, D. J. \& Davies, D. L. (1983). Production and characteristics of antisera to Spiroplasma citri and clover phyllody-associated antigens derived from plants. Ann Appl Biol 103, 251-259.

Clark, M. F., Morton, A. \& Buss, S. L. (1989). Preparation of mycoplasma immunogens from plants and a comparison of polyclonal and monoclonal antibodies made against primula yellows MLO-associated antigens. Ann Appl Biol 114, 111-124.

Cleveland, D. W., Fischer, S. G., Kirschner, M. W. \& Laemmli, U. K. (1977). Peptide mapping by limited proteolysis in sodium dodecyl sulfate analysis by gel electrophoresis. J Biol Chem 252, 11021106.

Hofmann, K. \& Stoffel, W. (1993). TMbase - a database of membrane spanning protein segments. Biol Chem Hoppe-Seyler 374, 166.

Keane, G., Edwards, E. \& Clark, M. F. (1996). Differentiation of group 16Sr-IB aster yellows phytoplasmas with monoclonal antibodies. In Diagnostics in Crop Production (BCPC Symposium Series no. 65), pp. 263-268. Edited by G. Marshall. Farnham, Surrey, UK: The British Crop Protection Council.

Kuske, C. R. \& Kirkpatrick, B. C. (1992). Phylogenetic relationships between the western aster yellows mycoplasmalike organism and other prokaryotes established by $16 \mathrm{~S}$ rRNA gene sequences. Int J Syst Bacteriol 42, 226-233.

Laemmli, U. K. (1970). Cleavage of structural proteins during the assembly of the head of bacteriophage T4. Nature 227, 680-685.

Lee, I.-M., Davis, R. E. \& Gunderson-Rindal, D. E. (2000). Phytoplasma: phytopathogenic mollicutes. Annu Rev Microbiol 54, 221-255.

Lefol, C., Caudwell, A., Lherminier, J. \& Larrue, J. (1993). Attachment of the flavescence dorée pathogen (MLO) to leafhopper vectors and other insects. Ann Appl Biol 123, 611-622.

Lischwe, M. A. \& Ochs, D. (1982). A new method for partial peptide mapping using $\mathrm{N}$-chlorosuccinimide/urea and peptide silver staining in sodium dodecyl sulphate-polyacrylamide gels. Anal Biochem 127, 453-457.

Lorenz, K. H., Schneider, B., Ahrens, U. \& Seemüller, E. (1995). Detection of the apple proliferation and pear decline phytoplasmas by PCR amplification of ribosomal and nonribosomal DNA. Phytopathology 85, 771-776.

Marcone, C., Neimark, H., Ragozzino, A., Lauer, U. \& Seemüller, E. (1999). Chromosome sizes of phytoplasmas composing major phylogenetic groups and subgroups. Phytopathology 89, 805-810.

Marcone, C., Lee I.-M., Davis, R. E., Ragozzino, A. \& Seemüller, E. (2000). Classification of aster yellows-group phytoplasmas based on combined analyses of rRNA and tuf gene sequences. Int J Syst Evol Microbiol 50, 1703-1713.

McCoy, R. E., Caudwell, A., Chang, C. J. \& 16 other authors (1989). Plant diseases associated with Mycoplasma-like organisms. In The Mycoplasmas, vol. V, pp. 546-623. Edited by R. F. Whitcomb \& J. G. Tully. San Diego, CA: Academic Press.

Milne, R. G., Ramassso, E., Lenzi, R., Masenga, V., Sarindu, N. \& Clark, M. F. (1995). Pre- and post-embedding immunogold labelling and electron microscopy in plant host tissues of three antigenically unrelated MLOs: primula yellows, tomato big bud and bermudagrass white leaf. Eur J Plant Pathol 101, 57-67.

Nakai, K. \& Kanehisa, M. (1991). Expert systems for predicting protein localization sites in Gram-negative bacteria. Proteins Struct Funct Genet 11, 95-110.

Neimark, H. \& Kirkpatrick, B. C. (1993). Isolation and characterization of full-length chromosomes from non-culturable plantpathogenic Mycoplasma-like organisms. Mol Microbiol 7, 21-28. Nielsen, H., Engelbrecht, J., Brunak, S. \& von Heijne, G. (1997). 
Identification of prokaryotic and eukaryotic signal peptides and prediction of their cleavage sites. Protein Eng 10, 1-6.

Ochman, H., Medhora, M. M., Garza, D. \& Hartl, D. L. (1990). Amplification of flanking sequences by inverse PCR. In PCR Protocols: a Guide to Methods and Applications, pp. 219-227. Edited by M. A. Innis, D. H. Gelfand, J. J. Sninsky \& T. J. White. San Diego, CA: Academic Press.

Olsson, A., Eliasson, M., Guss, B., Nilsson, B., Hellman, U., Lindberg, M. \& Uhlen, M. (1987). Structure and evolution of the repetitive gene encoding streptococcal protein G. Eur J Biochem 168, 319-324.

Posnette, A. F. \& Ellenberger, C. E. (1963). Further studies of green petal and other leafhopper transmitted viruses infecting strawberry and clover. Ann Appl Biol 51, 69-83.

Razin, S. \& Jacobs, E. (1992). Mycoplasma adhesion. J Gen Microbiol 138, 407-422.

Sambrook, J., Fritsch, E. F. \& Maniatis, T. (1989). Molecular Cloning: a Laboratory Manual, 2nd edn. Cold Spring Harbor, NY: Cold Spring Harbor Laboratory.

Sauer-Eriksson, A. E., Kleywegt, G. J., Uhlen, M. \& Jones, T. A. (1995). Crystal structure of the C2 fragment of streptococcal protein $\mathrm{G}$ in complex with the Fc domain of human IgG. Structure 3, 265-278.
Seddas, A., Meignoz, R., Daire, X. \& Boudon-Padieu, E. (1996). Generation and characterization of monoclonal antibodies to flavescence dorée phytoplasma: serological relationships and differences in electroblot immunoassay profiles of flavescence dorée and elm yellows phyoplasmas. Eur J Plant Pathol 102, 757-764.

Seemüller, E., Marcone, C., Lauer, U., Ragozzino, A. \& Göschl, M. (1998). Current status of molecular classification of the phytoplasmas. J Plant Pathol 80, 3-26.

Vibio, M., Bertaccinin, A., Lee, I.-M., Davis, R. E. \& Clark, M. F. (1996). Differentiation and classification of aster yellows and related European phytoplasmas. Phytopathol Mediterr 35, 33-42.

von Heijne, G. (1990). The signal peptide. J Membr Biol 115, 195-201.

Yu, Y.-L., Yeh, K.-W. \& Lin, C.-P. (1998). An antigenic protein gene of a phytoplasma associated with sweet potato witches' broom. Microbiology 144, 1257-1262.

Yu, J., Wayadande, A. C. \& Fletcher, J. (2000). Spiroplasma citri surface protein P89 implicated in adhesion to cells of the vector Circulifer tenellus. Phytopathology 90, 716-722.

Received 2 March 2001; revised 23 July 2001; accepted 24 August 2001. 